\title{
Photoinduced Absorption in Bismuth Titanate Crystals on Nano- and Picosecond Excitation"
}

\author{
A. V. Stankevich, A. L. Tolstik*, and Haider Kamil Hanoon \\ Belarussian State University, Minsk, 220030 Belarus \\ *e-mail: tolstik@bsu.by \\ Received March 11, 2011
}

\begin{abstract}
The peculiarities in the induced absorption of bismuth titanate $\left(\mathrm{Bi}_{12} \mathrm{TiO}_{20}\right)$ crystals upon their irradiation by high-intensity nano- and picosecond pulses with a wave length of $532 \mathrm{~nm}$ have been studied. The relationship between the photochromic effect and radiation intensity at the fixed radiation dose in conditions of pulsed laser excitation has been established. A threshold character of the relationship between the photochromic effect and intensity has been found for the first time. A phenomenological model making it possible to explain qualitatively the dynamics of the trapping level population process has been proposed.
\end{abstract}

DOI: $10.1134 / \mathrm{S} 1063785011080268$

The creation of measuring systems based on recording of dynamic gratings in photorefractive media enables one to realize both the interferometric principles of highly sensitive recording and the principles of adaptivity to noise effects. To improve the potentialities of photorefractive holographic devices, it is expedient to develop the control method for sensitivity of photorefractive materials over a wide spectral range. The photochromic effect consisting in reversible changes of the optical absorption of a crystal subjected to visible or near UV radiation seems to be a mechanism of widening the spectral sensitivity region $[1,2]$. The photochromic effect is caused by recharging of the defect centers with different photoionization cross-sections, some of them playing a role of donors and others being traps for the carriers [3].

Among various photorefractive materials, most interesting are the crystals of bismuth titanate $\mathrm{Bi}_{12} \mathrm{TiO}_{20}$ (BTO) having the structure of sillenite that, owing to its photoconduction properties, may be used in manufacturing of devices for optical memory, dynamic holography, integral and nonlinear optics [1, $2,4,5]$. The photoinduced light absorption in crystals of the sillenite-family is usually studied using radiation of semiconductor light-emitting diodes (LED) or lamps with a wide or narrow radiation spectrum [6-9]. For example, a dynamics of the photoinduced absorption in calcium-doped bismuth titanate crystals was studied when these crystals were subjected to quasimonochromatic optical radiation of semiconductor LED at different wavelengths [6, 7]. A model for recharging of the defect centers was proposed to describe the observed effects [6]. The material parameters of the crystals were estimated with regard to the doubly-ionized donor centers and sallow traps [7].

\footnotetext{
"The article was translated by the authors.
}

The induced absorption when photorefractive crystals of bismuth titanate were exposed to continuous laser radiation at a wavelength of $514 \mathrm{~nm}$ was analyzed in [10], and also the dynamic characteristics of photoinduced processes were determined. The works devoted to studies of the induced absorption on pulsed excitation are few in number. For example, in [11, 12] the spectral dependences of the photoinduced absorption in bismuth titanate crystals subjected to the effect of nanosecond laser pulses (wavelength $532 \mathrm{~nm}$ ) were estanlished. The relationship between the induced absorption and exposure was revealed, and a model for population of two trapping levels was proposed to describe adequately the experimental results [11].

This work presents a study of the induced absorption in bismuth titanate crystals subjected to nanoand picosecond laser pulses with variable intensity at $532 \mathrm{~nm}$, and also a phenomenological model providing a qualitative explanation for dynamics of the trapping-level population process.

The induced absorption effect was studied using the bismuth titanate crystals $1.5 \mathrm{~mm}$ thick which were subjected to picosecond, nanosecond, and continuous radiation with the wavelength $532 \mathrm{~nm}$. The use of three laser sources has enabled covering of the intensity ranges $1-15 \mathrm{~W} / \mathrm{cm}^{2}$ (continuous wave lasing) and tens of $\mathrm{kW} / \mathrm{cm}^{2}$ to hundreds of $\mathrm{MW} / \mathrm{cm}^{2}$ (pulsed irradiation).

To establish the conditions required for the photochromic effect exhibition, the authors have measured the absorption spectra of a bismuth titanate crystal before and after its laser irradiation at different exposures (Fig. 1). As seen from the experimental data, the induced absorption factor was changing considerably for exposures above $250 \mathrm{~J} / \mathrm{cm}^{2}$ in the case of nanosec- 

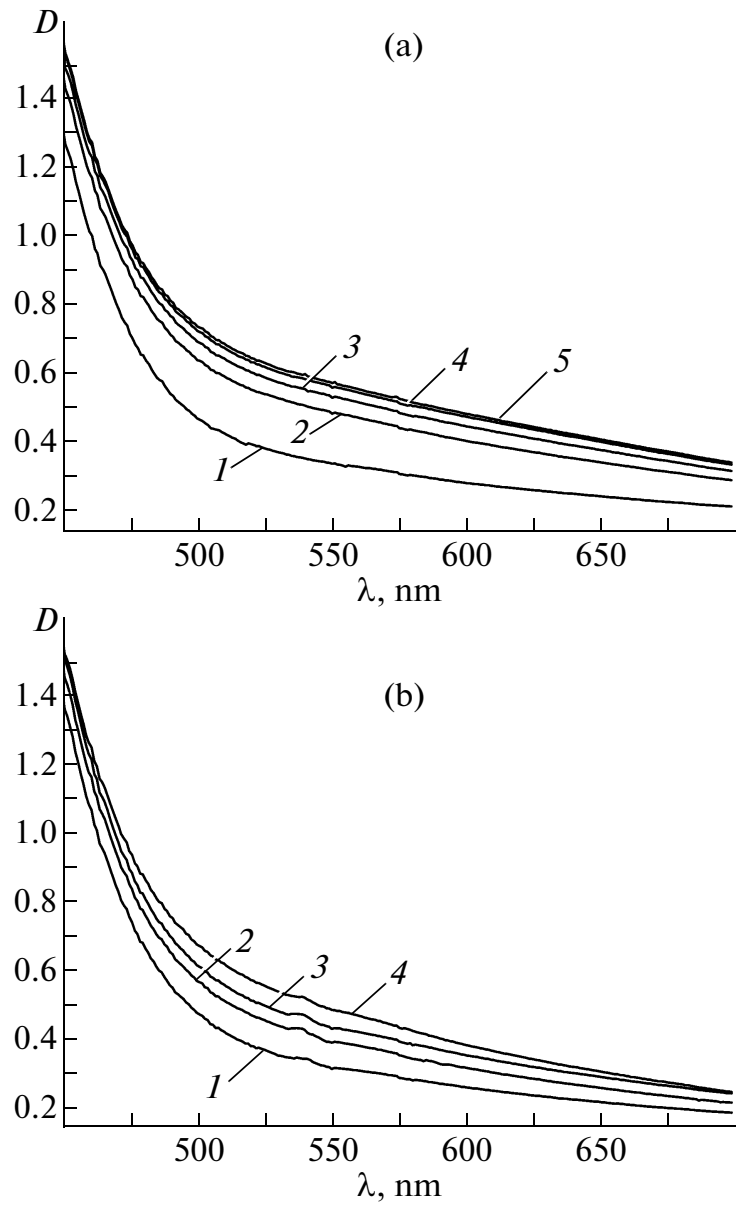

Fig. 1. Absorption spectra of bismuth titanate crystal subjected to (a) nano- and (b) picosecond radiation: (a) exposure at $0(1), 250(2), 500(3), 750(4)$, and $1000 \mathrm{~J} / \mathrm{cm}^{2}$ (5) with the peak intensity of laser pulses $1 \mathrm{MW} / \mathrm{cm}^{2}$; (b) exposure at $0(1), 15(2), 30(3)$, and $50 \mathrm{~J} / \mathrm{cm}^{2}$ (4) with the peak intensity of laser pulses $50 \mathrm{MW} / \mathrm{cm}^{2}$.

ond radiation and above $15 \mathrm{~J} / \mathrm{cm}^{2}$ in the case of picosecond radiation.

A more detail analysis of the features of the photochromic effect exhibition on pulsed excitation was performed based on investigations into the relationship between the crystal optical density and radiation intensity at the fixed exposure (Fig. 2). With the use of a laser generating nanosecond pulses (pulse length $25 \mathrm{~ns}$, pulse repetition rate $10 \mathrm{~Hz}$ ), the average energy of a single pulse during the experiment was varying from 1 to $40 \mathrm{~mJ} / \mathrm{cm}^{2}$, making it possible to change the peak intensity at the input face of the crystal between 0.04 and $1.6 \mathrm{MW} / \mathrm{cm}^{2}$, the exposure being $500 \mathrm{~J} / \mathrm{cm}^{2}$. As seen in Fig. 2a, the induced absorption is growing with the peak intensity, reaching saturation at the intensity $\sim 1.5 \mathrm{MW} / \mathrm{cm}^{2}$. The measured dependence was distinguished by its threshold character. At the intensities of laser pulses below $0.05 \mathrm{MW} / \mathrm{cm}^{2}$ no pho-
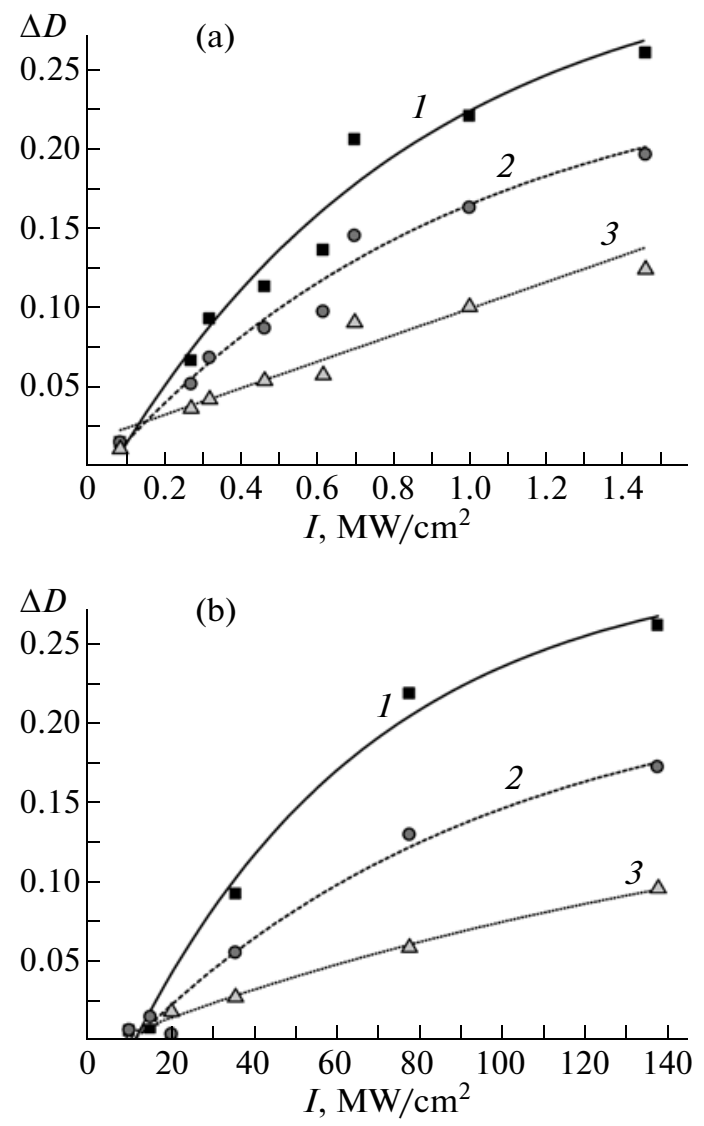

Fig. 2. Changes in the optical density at wavelengths $500(1), 600(2)$, and $700 \mathrm{~nm}(3)$ as a function of the incident pulse intensity for bismuth titanate crystal subjected to (a) nano- and (b) picosecond radiation at an exposure of 500 and $17 \mathrm{~J} / \mathrm{cm}^{2}$, respectively.

tochromic effect was observed even at high radiation doses (above $1000 \mathrm{~J} / \mathrm{cm}^{2}$ ).

To study the effect of the photoinduced absorption at higher intensities $I>10 \mathrm{MW} / \mathrm{cm}^{2}$, a picosecond laser with the active mode locking was used, generating the pulses $70 \mathrm{ps}$ in length at the repetition rate $15 \mathrm{~Hz}$. In the process the average energy in a pulse was varying from 0.7 to $10 \mathrm{~mJ} / \mathrm{cm}^{2}$, whereas the peak intensity at the input face of the crystal was ranging from 10 to $140 \mathrm{MW} / \mathrm{cm}^{2}$. The radiation exposure was fixed coming to $17 \mathrm{~J} / \mathrm{cm}^{2}$. As seen in Fig. $2 \mathrm{~b}$, on going to picosecond pulses a qualitative character of the observed function was retained, while the quantitative parameters of the photochromic effect were changing. The absorption effect was observed at the intensities over $100 \mathrm{MW} / \mathrm{cm}^{2}$, the threshold intensity being in excess of $10 \mathrm{MW} / \mathrm{cm}^{2}$.

For comparison, Fig. 3 gives the recalculated changes in the optical density as a function of the incident pulse energy. As seen, at close threshold energies $\left(\sim 1 \mathrm{~mJ} / \mathrm{cm}^{2}\right)$ the identical effect (optical density 


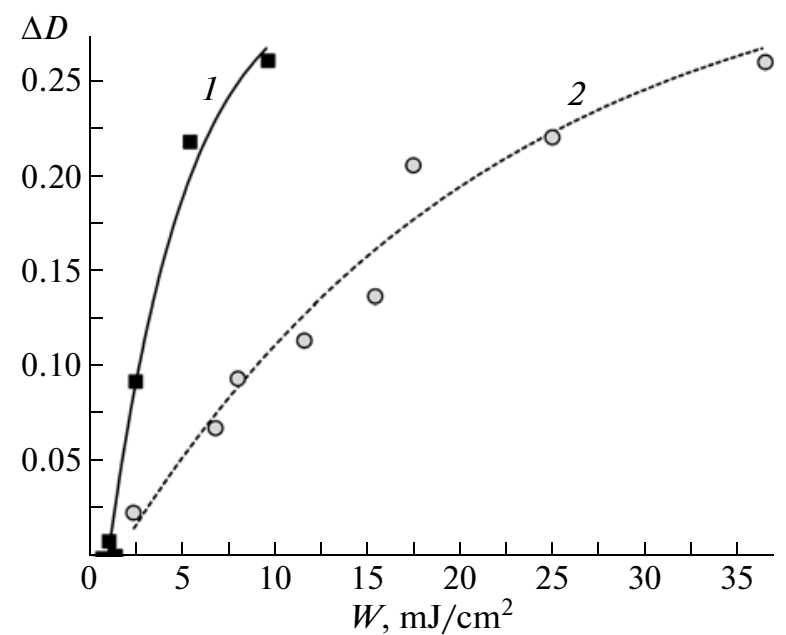

Fig. 3. Changes in the optical density at wavelength $500 \mathrm{~nm}$ as a function of the incident pulse energy for bismuth titanate crystal subjected to (1) pico- and (2) nanosecond radiation.

change $\Delta D \approx 0.25$ ) was achieved for picosecond pulses at a significantly lower energy of the pulses (by a factor of 5) and exposure (by a factor of 30).

For comparison, the crystal of bismuth titanate was also subjected to a continuous laser radiation with the same wavelength $532 \mathrm{~nm}$, the intensity varying over the range from 1 to $15 \mathrm{~W} / \mathrm{cm}^{2}$. Regardless of high exposures (above $2000 \mathrm{~J} / \mathrm{cm}^{2}$ ), no induced absorption was observed. However, irradiation of the previously darkened crystal has resulted in the inverse effectreduction in the induced absorption.

For explanation of the obtained results, a phenomenological model was developed based on two concurrent interaction mechanisms between laser radiation and photorefractive crystals. A phenomenon of the induced absorption is associated with electron transitions on photoexcitation from the valence band to the conduction band with subsequent relaxation to the long-lived energy levels (traps) located within the forbidden band. These additionally emerging absorption centers lead to the increased absorption factor that was initially attributed to the electron transitions from the valence band to the conduction one. As trapping levels are positioned above the valence band, one can observe an appreciable increase of absorption in the long wavelength spectral region. The traps themselves are conditioned by impurities and defects occurring within the crystal bulk and supported by spectral investigations. A width of the forbidden band for the bismuth titanate crystal was equal to $3.57 \mathrm{eV} \mathrm{[14],} \mathrm{pre-}$ venting the realization of a direct band-to-band transition for the photons at the wavelength $532 \mathrm{~nm}$ (quantum energy $2.33 \mathrm{eV}$ ).

Growing intensity results in the processes of twophoton or two-quanta (cascade) light absorption the probability of which is proportional to the squared intensity of incident radiation. They lead to transition of the electrons to the conduction band, from where they, with a certain probability, settle out at the longlived trapping levels of the forbidden band or return to the valence band. Population of trapping levels results in the optical darkening effect. Because the energy gap between the long-lived trapping levels and conduction band is below the energy of an energy quantum, there is a possibility for the light-induced single-quantum electron transition from trapping levels into the conduction band, from where the electrons can return to the trapping levels or to the valence band. The latter case is associated with the optical bleaching effect. Concurrence of the single- and two-quantum processes is responsible for a threshold character of the relationship between the photochromic effect and radiation intensity, and involvement of the cascade absorption processes accounts for the fact that at lower energy the picosecond pulses offer the same darkening efficiency as the nanosecond ones at higher energy (Fig. 3).

In this way the work performed has demonstrated the relationship between the induced absorption in bismuth titanate crystals and incident intensity in conditions of nano- and picosecond excitation. A threshold character of the photochromic effect-intensity dependence has been found for the first time, the threshold values of the intensity $\left(I_{\mathrm{th}} \approx 0.05 \mathrm{MW} / \mathrm{cm}^{2}\right.$ and $I_{\mathrm{th}} \approx 15 \mathrm{MW} / \mathrm{cm}^{2}$ for nano- and picosecond radiation, respectively) and also of the laser pulse energy density $\left(\sim 1 \mathrm{~mJ} / \mathrm{cm}^{2}\right)$ have been determined.

Acknowledgments. The authors are very grateful to Prof. S.M. Shandarov (Tomsk State University of Control Systems and Radioelectronics) and A.Yu. Matusevich (Fr. Shiller Jena University) for valuable discussions and assistance in the process of the work preparation.

\section{REFEFRENCES}

1. V. K. Malinovskii, O. A. Gudaev, V. A. Gusev, and S. I. Demenko, Photinduced Phenomena in Sillenites (Nauka, Novosibirsk, 1990) [in Russian].

2. Yu. F. Kargin, V. I. Burkov, A. A. Mar'in, and A. V. Egorysheva, Crystals with Sillenite Structure: Synthesis, Composition, Properties (Russ. Acad. Sci., Moscow, 2004) [in Russian].

3. O. V. Kobozev, S. M. Shandarov, A. A. Kamshilin, and V. V. Prokofiev, J. Opt. A: Pure Appl. Opt. 1, 442 (1999).

4. E. Nippolainen, V. V. Prokofiev, A. A. Kamsyilin, and T. Jaaskelainen, Appl. Phys. B 69, 45 (1999).

5. N. I. Nazhestkina, A. A. Kamsyilin, O. V. Kobozev, and V. V. Prokofiev, Appl. Phys. B 72, 767 (2001). 
6. A. E. Mandel', A. M. Plesovskii, S. M. Shandarov, et al., Izv. Vyssh. Ucheb. Zaved., Fiz., No. 12, 48 (2003) [Russ. Phys. J. 46, 1237 (2003)].

7. S. M. Shandarov, A. E. Mandel', A. V. Kazarin, et al., Izv. Vyssh. Ucheb. Zaved., Fiz., No. 8, 29 (2002) [Russ. Phys. J. 45, 763 (2002].

8. J. S. McCullough, A. L. Harmon Bauer, C. A. Hunt, and J. J. Martin, J. Appl. Phys. 90, 6017 (2001).

9. A. W. Wood, C. A. Hunt, and J. J. Martin, J. Appl. Phys. 101, 063517 (2007).
10. A. Matusevich, A. Tolstik, M. Kisteneva, et al., Appl. Phys. B 96, 119 (2009).

11. A. L. Tolstik, A. Yu. Matusevich, M. G. Kisteneva, et al., Kvantovaya Elektron. (Moscow) 37, 1027 (2007) [Quant. Electron. 37, 1027 (2007)].

12. A. Matusevich, A. Tolstik, M. Kisteneva, et al., Appl. Phys. B 92, 219 (2008).

13. A.V. Egorysheva, Zh. Neorg. Khim. 50, 461 (2005). 